\title{
IMPROOF: Integrated model guided process optimization of steam cracking furnaces
}

Marko R. Djokic ${ }^{1, *}$, Kevin M. Van Geem ${ }^{1}$, Geraldine J. Heynderickx ${ }^{1}$, Stijn Dekeukeleire $^{1}$, Stijn Vangaever ${ }^{1}$, Frederique Battin-Leclerc ${ }^{2}$, Georgios Bellos ${ }^{3}$, Wim Buysschaert $^{4}$, Benedicte Cuenot ${ }^{5}$, Tiziano Faravelli ${ }^{6}$, Michael Henneke ${ }^{7}$, Dietlinde Jakobi ${ }^{8}$, Philippe Lenain ${ }^{9}$, Andres Munoz ${ }^{10}$, John Olver ${ }^{11}$, Marco Van Goethem ${ }^{12}$, and Peter Oud $^{12}$

\author{
${ }^{1}$ Laboratory for Chemical Technology, Ghent University, Ghent, Belgium \\ \{marko.djokic, kevin.vangeem, geraldine.heynderickx, stijn. \\ dekeukeleire, stijn.vangaever\} @ugent.be \\ ${ }^{2}$ Centre National de la Recherche Scientifique, Nancy, France \\ frederique.battin-leclerc@univ-lorraine.fr \\ ${ }^{3}$ DOW Benelux B.V., Terneuzen, The Netherlands \\ bellosedow.com \\ ${ }^{4}$ CRESS B.V., Breskens, The Netherlands \\ Wim.Buysschaertecressbv.nl \\ ${ }^{5}$ European Centre for Research and Advanced Training in Scientific Computation, Toulouse, \\ France \\ benedicte. cuenotecerfacs.fr \\ ${ }^{6}$ Politecnico di Milano, Milan, Italy \\ tiziano.faravelli@polimi.it \\ ${ }^{7}$ John Zink International Luxembourg SARL, Luxembourg \\ Michael.Henneke@johnzink.com \\ ${ }^{8}$ Schmidt + Clemens $\mathrm{GmbH}+\mathrm{CO} . \mathrm{KG}$, Lindlar, Germany \\ d.jakobieschmidt-clemens.de \\ ${ }^{9}$ Ayming Belgium, Brussels, Belgium \\ plenain@ayming. com \\ ${ }^{10}$ AVGI, Ghent, Belgium \\ andres. munoz@avgi.be \\ ${ }^{11}$ Emisshield Inc., Blacksburg, Virginia, USA \\ john.olver@emisshield.com \\ 12 TECHNIP Benelux B.V., Zoetermeer, The Netherlands \\ \{mvangoethem, poud\}@technip.com
}

\begin{abstract}
IMPROOF will develop and demonstrate the steam cracking furnace of the $21^{\text {st }}$ century by drastically improving the energy efficiency of the current state-of-the-art, in a cost effective way, while simultaneously reducing emissions of greenhouse gases and $\mathrm{NOx}$ per ton of ethylene produced by at least $25 \%$. Therefore, the latest technological innovations in the field of energy efficiency and fouling minimization are implemented and combined, proving that these technologies work properly at TRL 5 and 6 levels. The first steps to reach the ultimate objective, i.e. to deploy the furnace at the demonstrator at commercial scale with the most effective technologies, will be discussed based on novel pilot scale data and modeling results.
\end{abstract}

